Available Online at https://ejournal.unib.ac.id/index.php/labsaintek/index DOI: https://doi.org/10.33369/labsaintek.v1i1.15433

\title{
PERBANDINGAN PENGGUNAAN SASAK BERBAHAN KAYU DAN BESI TERHADAP KECEPATAN PENGERINGAN HERBARIUM DI LABORATORIUM BIOLOGI, UNIVERSITAS BENGKULU
}

\author{
${ }^{1}$ Dedi Susanto, ${ }^{2}$ Lies Winarsih, ${ }^{3}$ Rochmah Supriati \\ ${ }^{1}$ PLP Laboratorium Biologi, sub Lab Tumbuhan FMIPA Universitas Bengkulu \\ ${ }^{2}$ PLP Laboratorium Biologi, sub Lab Ekologi FMIPA Universitas Bengkulu \\ ${ }^{3}$ Jurusan Biologi FMIPA Universitas Bengkulu
}

Korespondensi: susantod007@gmail.com

\begin{abstract}
Abstrak
Tujuan dari penelitian ini adalah untuk mengetahui kecepatan pengeringan dalam proses pembuatan herbarium dengan menggunakan tiga jenis sasak : sasak berbahan kayu, sasak berbahan besi plat dan sasak berbahan besi bulat batangan. Penelitian ini merupakan jenis penelitian eksperimental yang dilakukan dengan mengeringkan spesimen tanaman sirih pada suhu $50^{\circ} \mathrm{C}$ dengan waktu pengeringan $3 \times 24$ jam. Alat pengering yang digunakan adalah oven. Untuk mengetahui kestabilan pengoperasian oven digunakan stop kontak timer. Untuk mengetahui kadar air tanaman sirih digunakan neraca analitik. Hasilnya adalah jenis sasak terhadap kecepatan pengeringan terbaik menurut urutan adalah : 1) sasak besi bulat batangan, 2) sasak kayu, 3) sasak besi plat. Sedangkan jenis sasak terhadap kualitas spesimen terbaik menurut urutan adalah : 1) sasak kayu, 2) sasak besi bulat batangan, 3) sasak plat besi.
\end{abstract}

Abstract

The purpose of this study was to determine the speed of drying in the herbarium making process using three types of sasak: wooden sasak, plate iron sasak and round iron bars. This research is an experimental type of research conducted by drying betel plant specimens at a temperature of $50 \mathrm{oC}$ with a drying time of $3 \times 24$ hours. The dryer used is an oven. To determine the stability of the operation of the oven, a timer socket is used. To determine the water content of betel plants, an analytical balance is used. The result is that the type of sasak with the best drying speed according to the order is: 1) round iron sasak, 2) wooden sasak, 3) plate iron sasak. While the types of sasak to the best specimen quality according to the order are: 1) wooden sasak, 2) round iron sasak, 3) iron plate sasak.

\section{PENDAHULUAN}

Proses pembuatan herbarium kering yang umum digunakan adalah pengeringan dalam tekanan. Dalam proses ini, spesimen yang akan dikeringkan disusun dan ditekan dengan menggunakan alat penekan yang disebut dengan sasak. Penekanan dimaksudkan untuk menjaga kondisi spesimen agar tidak berubah, tidak bergerak, atau terlipat selama proses pengeringan. Selain itu penekanan ini juga berfungsi untuk mempercepat proses 
pengeringan. Sasak yang digunakan dapat dibuat dari berbagai bahan, misalnya triplek, bambu, kayu atau logam (Bandingkan Heri Sudjatmiko dan Titi Kalima).

Saat ini sasak yang tersedia di laboratorium Biologi terbuat dari kayu, sedangkan diketahui bahwa kayu memiliki konduktivitas panas yang rendah. Di sisi lain memungkinkan untuk membuat sasak dari bahan logam yang memiliki konduktivitas panas jauh lebih tinggi. Untuk mengetahui dan membandingkan konduktivitas panas beberapa jenis kayu dan beberapa jenis logam dapat dilihat pada tabel berikut ini.

Tabel 1. Konduktivitas termal untuk berbagai logam (Zemansky, 2002)

\begin{tabular}{lcc}
\hline & Bahan & $\mathbf{k}\left(\mathbf{W} / \mathbf{m}^{\mathbf{0}} \mathbf{C}\right)$ \\
\hline Aluminium & 205,0 \\
Kuningan & 109,0 \\
Tembaga & 385 \\
Timbal & 34,7 \\
Perak & 406,0 \\
Baja & 50,2 \\
Raksa & 8,3 \\
Besi & 73 \\
\hline
\end{tabular}

*Irnin Agustina Dwi Astuti

Tabel 2. Nilai konduktivitas termal untuk kayu akasia, kayu jati dan kayu mahoni

\begin{tabular}{lll}
\hline No. & Jenis Kayu & $\begin{array}{l}\text { Nilai koefisien konduktivitas termal } \\
\left(\mathbf{x 1 0}^{-\mathbf{1}} \mathbf{W} / \mathbf{m}^{\mathbf{0}} \mathbf{C}\right)\end{array}$ \\
\hline 1 & Akasia & $2,9 \pm 0,3$ \\
2 & Jati & $2,1 \pm 0,3$ \\
3 & Mahoni & $3,6 \pm 0,4$ \\
\hline
\end{tabular}

*Antonius Dian Pratama

Tabel 1 memberikan informasi tentang koefisien konduktivitas termal beberapa jenis logam. Tabel 2 memberikan informasi tentang koefisien konduktivitas termal beberapa jenis kayu. Dari delapan contoh logam yang ditampilkan oleh tabel 1, koefisien konduktivitas termal delapan contoh logam tersebut berada di antara $8,3-385 \mathrm{~W} / \mathrm{m}^{\circ} \mathrm{C}$. Di sisi lain, dari 3 contoh kayu yang ditampilkan di tabel 2 memperlihatkan nilai koefisien konduktivitas termal berada di antara $0,21-0,36 \mathrm{~W} / \mathrm{m}^{\circ} \mathrm{C}$. Dari kedua data ini kita bisa melihat bahwa koefisien konduktivitas termal logam nilainya mencapai 40 - 1000 kali lebih besar dari pada koefisien konduktivitas termal kayu, dalam artian bahwa logam lebih baik dalam menghantarkan panas 40 - 1000 kali dari pada kayu.

Dalam kaitannya dengan proses pengeringan spesimen herbarium, proses ini sendiri sepenuhnya mengandalkan proses perpindahan panas. Karena itu keberadaan dan kestabilan sumber panas menjadi sangat penting dalam proses pengeringan spesimen herbarium, baik itu yang berasal dari sinar matahari, panas api dari kayu/arang atau pemanas listrik. Dengan digunakannya kayu sebagai sasak, maka media penyalur panas sepenuhnya tergantung pada udara yang mengalir dari pemanas lalu naik ke atas ke saluran pembuangan. Keberadaan sasak sendiri tidak dapat diharapkan membantu proses pemindahan panas dan hanya berfungsi sebagai penekan saja. Penggantian sasak berbahan kayu dengan sasak berbahan logam dapat diharapkan memberikan fungsi ganda selain sebagai alat penekan juga berfungsi sebagai penerima panas dari udara yang mengalir yang kemudian dialirkan ke lapisan spesimen yang berhimpitan langsung dengan sasak. Hal ini dapat berpotensi menjadi penyalur panas yang lebih baik yang dapat diharapkan mempercepat proses pengeringan.

\section{TUJUAN PENELITIAN}


Penelitian yang membandingkan penggunaan sasak kayu dan sasak besi ini memiliki tujuan sebagai berikut :

1. Mendapatkan jenis sasak yang lebih cepat mengeringkan spesimen herbarium.

2. Mendapatkan jenis sasak yang menghasilkan spesimen herbarium kering dalam kondisi terbaik.

3. Mendapatkan jenis sasak yang paling ekonomis dan efisien terhadap oven dan daya listrik.

\section{METODE PENELITIAN}

Penelitian ini merupakan penelitian eksperimen dengan 1 (satu) faktor, yaitu jenis bahan sasak yang terbagi menjadi 3 taraf faktor : 1) sasak kayu, 2) sasak besi plat, 3) sasak besi bulat batangan. Setiap perlakuan dicobakan tiga kali, dengan satu kali perlakuan menggunakan 4 spesimen.

Alat yang digunakan dalam penelitian ini adalah : 1) oven, 2) stop kontak timer, 3) sasak, 4) sprayer, 5) neraca analitik.

Bahan yang digunakan dalam penelitian ini adalah : 1) alkohol $70 \%$,2) tanaman sirih, 3) koran, 4) kardus, 5) tali rafia.

Penelitian ini dilakukan dengan cara kuantitatif dan visual. Analisa kuantitatif dilakukan dengan menimbang berat spesimen pada awal sebelum proses pembuatan herbarium, berat spesimen setelah 24 jam proses pengeringan, berat spesimen setelah $24 \times 2$ jam proses pengeringan dan berat spesimen setelah $24 \times 3$ jam proses pengeringan. Analisa visual dilakukan pada fisik spesimen setelah $24 \times 3$ jam proses pengeringan atau pada akhir penelitian, karena akhir dari proses ini dianggap sebagai hasil final dari spesimen herbarium.

Penelitian dilakukan di Laboratorium Biologi, sub lab Tumbuhan, FMIPA Universitas Bengkulu. Waktu penelitian dimulai.

\section{HASIL DAN PEMBAHASAN}

Hasil dari pengeringan dan penimbangan spesimen dapat dilihat pada tiga tabel berikut ini.

Tabel 3. Berat spesimen yang dikeringkan dengan sasak kayu

\begin{tabular}{|c|c|c|c|c|}
\hline \multirow{2}{*}{$\begin{array}{c}\text { Nomor } \\
\text { Spesimen }\end{array}$} & \multicolumn{4}{|c|}{ Waktu Pengeringan (jam) } \\
\cline { 2 - 5 } & O & $\mathbf{2 4}$ & $\mathbf{4 8}$ & 72 \\
\hline 1 & 12,66 & 3,85 & 2,68 & 2,66 \\
\hline 2 & 13,11 & 3,62 & 2,44 & 2,42 \\
\hline 3 & 14,19 & 4,56 & 2,76 & 2,75 \\
\hline 4 & 15,27 & 4,70 & 2,99 & 2,98 \\
\hline 5 & 13,69 & 4,52 & 3,01 & 2,96 \\
\hline 6 & 15,04 & 4,31 & 2,88 & 2,87 \\
\hline 7 & 13,58 & 5,27 & 3,24 & 3,21 \\
\hline 8 & 11,60 & 3,74 & 2,64 & 2,63 \\
\hline 9 & 15,77 & 4,32 & 3,81 & 3,78 \\
\hline 10 & 17,18 & 5,41 & 3,67 & 3,61 \\
\hline 11 & 10,21 & 2,75 & 1,98 & 1,96 \\
\hline 12 & 13,04 & 3,32 & 2,93 & 2,90 \\
\hline
\end{tabular}

Keterangan : berat spesimen dalam gram

Tabel 4. Berat spesimen yang dikeringkan dengan sasak besi plat 


\begin{tabular}{|c|c|c|c|c|}
\hline \multirow{2}{*}{$\begin{array}{c}\text { Nomor } \\
\text { Spesimen }\end{array}$} & \multicolumn{4}{|c|}{ Waktu Pengeringan (jam) } \\
\cline { 2 - 5 } & $\mathbf{0}$ & $\mathbf{2 4}$ & $\mathbf{4 8}$ & $\mathbf{7 2}$ \\
\hline 1 & 15,20 & 5,06 & 3,42 & 3,32 \\
\hline 2 & 10,42 & 4,13 & 2,32 & 2,22 \\
\hline 3 & 13,00 & 6,08 & 2,73 & 2,66 \\
\hline 4 & 15,28 & 6,27 & 3,33 & 3,25 \\
\hline 5 & 17,67 & 9,65 & 6,09 & 4,28 \\
\hline 6 & 11,24 & 6,37 & 4,96 & 2,88 \\
\hline 7 & 10,44 & 6,32 & 4,28 & 2,44 \\
\hline 8 & 13,39 & 8,60 & 6,91 & 3,36 \\
\hline 9 & 14,03 & 8,15 & 3,81 & 3,26 \\
\hline 10 & 13,30 & 9,13 & 5,43 & 3,17 \\
\hline 11 & 14,03 & 10,32 & 5,68 & 4,00 \\
\hline 12 & 13,96 & 6,94 & 3,09 & 2,85 \\
\hline
\end{tabular}

Keterangan : berat spesimen dalam gram

Tabel 5. Berat spesimen yang dikeringkan dengan sasak besi bulat

\begin{tabular}{|c|c|c|c|c|}
\hline \multirow{2}{*}{$\begin{array}{c}\text { Nomor } \\
\text { Spesimen }\end{array}$} & \multicolumn{4}{|c|}{ Waktu Pengeringan (jam) } \\
\cline { 2 - 5 } & $\mathbf{0}$ & $\mathbf{2 4}$ & $\mathbf{4 8}$ & $\mathbf{7 2}$ \\
\hline 1 & 10,25 & 2,19 & 1,99 & 1,96 \\
\hline 2 & 12,60 & 3,82 & 2,87 & 2,86 \\
\hline 3 & 14,56 & 3,64 & 3,00 & 2,99 \\
\hline 4 & 14,10 & 3,81 & 3,15 & 3,13 \\
\hline 5 & 13,86 & 3,52 & 2,46 & 2,43 \\
\hline 6 & 13,93 & 3,64 & 2,91 & 2,89 \\
\hline 7 & 14,43 & 3,59 & 2,99 & 2,97 \\
\hline 8 & 12,26 & 3,09 & 2,66 & 2,53 \\
\hline 9 & 13,09 & 3,15 & 2,63 & 2,58 \\
\hline 10 & 13,85 & 3,18 & 2,46 & 2,46 \\
\hline 11 & 12,08 & 3,39 & 2,06 & 2,04 \\
\hline 12 & 14,63 & 4,29 & 3,29 & 3,26 \\
\hline
\end{tabular}

Keterangan : berat spesimen dalam gram

Data-data tersebut kemudian dirangkum dalam satu grafik yang membandingkan kecepatan pengurangan kadar air dari ketiga jenis sasak sebagai berikut :

Gambar 5. Tabel penguapan air pada penggunaan 3 jenis sasak

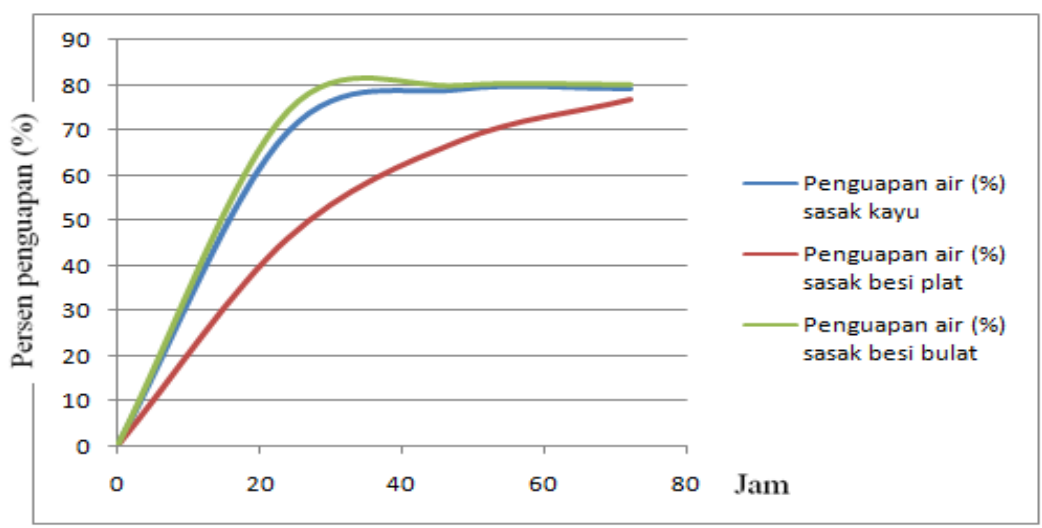

Dari grafik di atas terlihat bahwa penguapan air dengan menggunakan sasak besi bulat adalah yang tertinggi/tercepat. Selanjutnya penguapan air dengan menggunakan sasak kayu berada di posisi kedua dengan selisih yang tidak terlalu besar. Proses penguapan air yang paling lambat justru ditunjukkan oleh penggunaan sasak besi plat dengan selisih yang sangat besar.

Untuk proses pengeringan 24 jam, sasak besi bulat menghasilkan 74,19 \% penguapan kadar air, sasak kayu menghasilkan 69,59\% penguapan kadar air, dan sasak 
besi plat hanya menghasilkan $46,10 \%$ penguapan kadar air. Kadar air yang diuapkan sasak besi plat jauh di bawah penggunaan sasak kayu, lebih jauh lagi jika dibandingkan penggunaan sasak besi bulat. Hal ini berkebalikan dengan pengamatan kualitatif bahwa plat besi terasa jauh lebih panas dibandingkan sasak kayu, lapisan kertas dan kardus, bahkan masih lebih panas jika dibandingkan sasak besi bulat. Singkatnya, kondisi sasak plat besi adalah yang paling panas jika dibandingkan dua jenis sasak pembanding lainnya. Ternyata, kondisi yang lebih panas ini tidak berkorelasi positif terhadap laju penguapan air. Justru yang terjadi adalah sebaliknya, sasak yang paling panas justru menghasilkan proses penguapan yang paling lambat.

Tabel 6. Kadar air yang diuapkan

\begin{tabular}{|c|c|c|c|c|}
\hline \multirow{2}{*}{ Jenis Sasak } & \multicolumn{4}{|c|}{ Waktu Pengerngan (jam) } \\
\cline { 2 - 5 } & $\mathbf{0}$ & $\mathbf{2 4}$ & $\mathbf{4 8}$ & $\mathbf{7 2}$ \\
\hline Sasak kayu & 0 & 65,59 & 78,84 & 79,02 \\
\hline Sasak besi plat & 0 & 46,1 & 67,55 & 76,73 \\
\hline Sasak besi bulat & 0 & 74,19 & 79,74 & 79,94 \\
\hline
\end{tabular}

Keterangan : Kadar air yang diuapkan dalam persen (\%) terhadap bobot awal

Korelasi negatif ini diperkirakan terjadi akibat bentuk dari sasak besi plat itu sendiri yang berbentuk lembaran. Bentuknya yang lembaran membuatnya menutup rapat susunan lapisan spesimen yang berada di sebelah dalam. Sebagai penghantar panas hal ini berkorelasi positif karena plat besi menghantarkan panas secara merata ke spesimen tanpa celah kosong sedikitpun. Namun, sebagai media perpindahan uap air lembaran plat ini justru berdampak negatif karena menutup sebagian besar permukaan spesimen. Logam adalah zat padat yang tidak dapat dilalui oleh udara dan uap air, sehingga uap air dari spesimen tidak dapat bergerak melewati lembaran logam. Akibatnya uap air selama proses pengeringan terjebak di dalam lapisan sasak dan hanya bisa bergerak melalui tepi lapisan sasak yang sempit. Hal ini mengakibatkan luas area penguapan menjadi sangat sempit dan uap air terjebak di dalam lapisan koran dan kardus. 


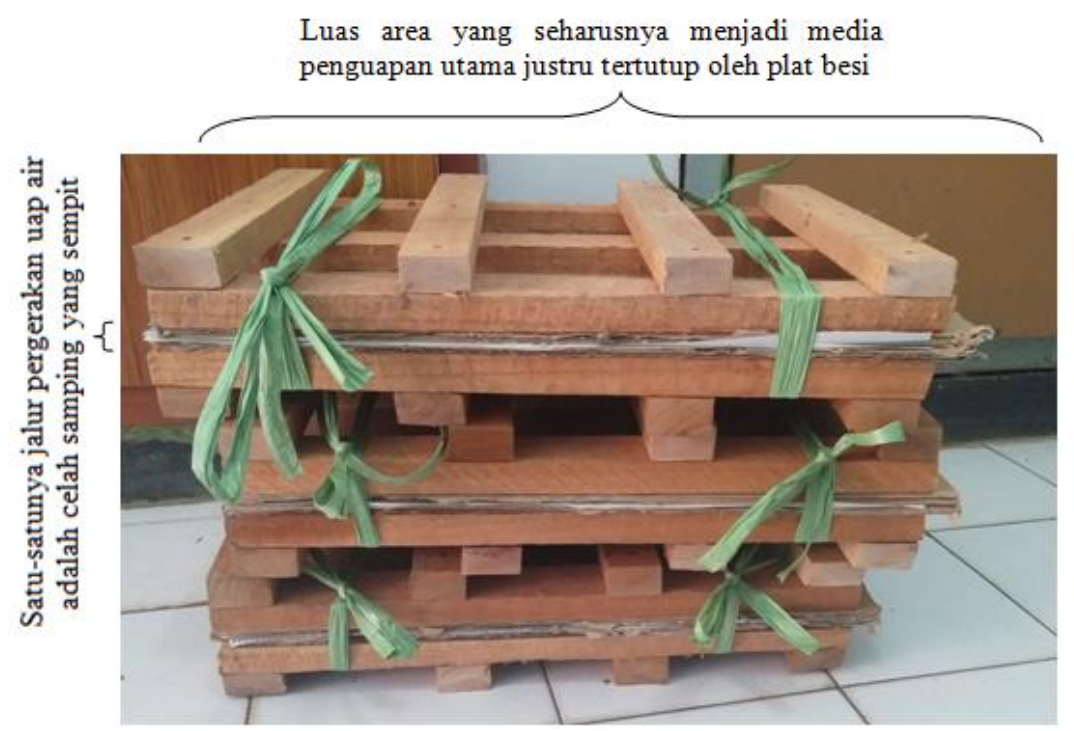

Gambar 9. Ilustrasi luas area penguapan yang tertutup oleh plat besi

Kondisi ini berbeda dengan sasak kayu dan sasak besi bulat yang keduanya terbuat dari kayu dan besi batangan, bukan kayu dan besi lembaran. Kedua sasak ini memiliki luas permukaan yang terbuka jauh lebih besar dari pada yang tertutup sasak. Efek negatif bentuk ini terhadap perpindahan panas adalah luas area konduksi yang tidak terlalu besar sehingga panas yang dihantarkan sasak besi kepada spesimen tidak terlalu besar. Namun, efek terhadap penguapan air jauh lebih baik karena uap air yang terbentuk tidak terhalang oleh lapisan besi dan bisa langsung mengalir ke udara dengan lancar.

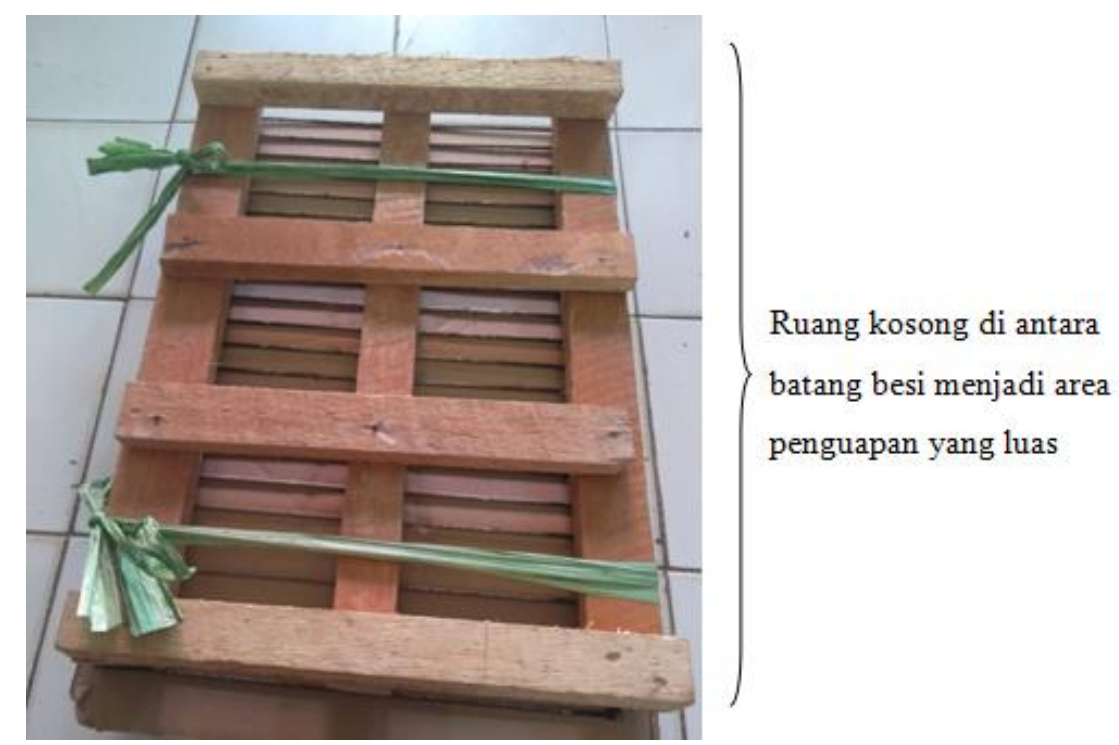

Gambar 10. Ilustrasi luas area penguapan uap air di sasak besi bulat

Analisa visual dilakukan dengan melihat kondisi spesimen tanaman sirih setelah 72 jam proses pengeringan. Berikut ini adalah contoh spesimen tanaman dari tiga jenis sasak yang digunakan. 


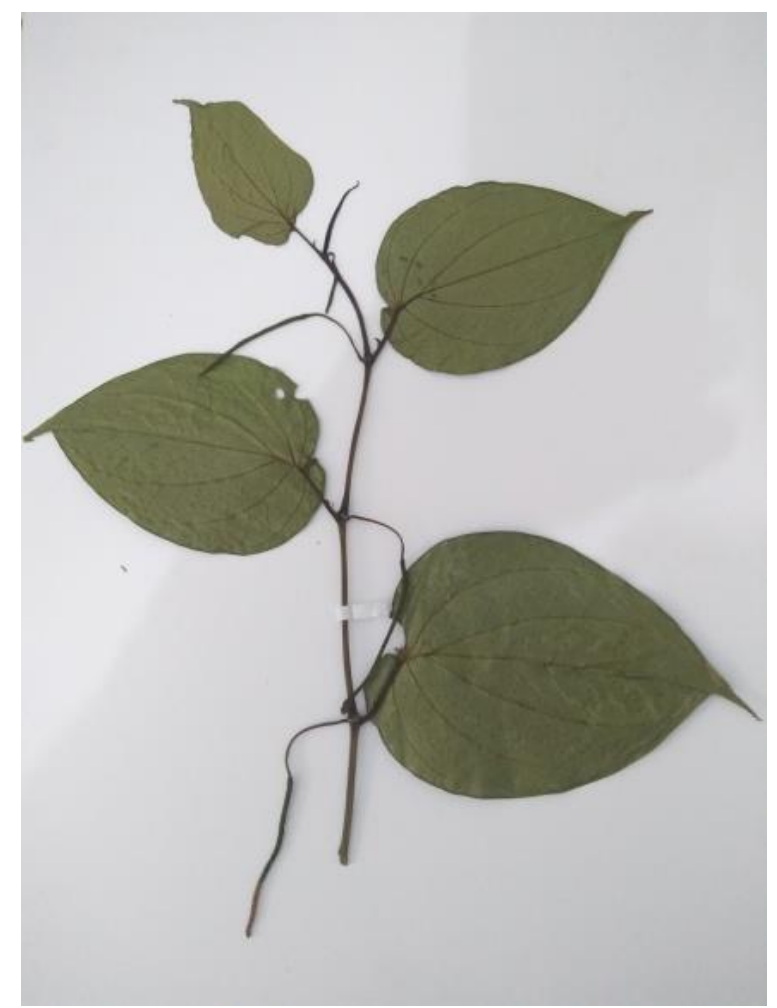

Gambar 11. Contoh spesimen tanaman sirih setelah 72 jam proses pengeringan dengan sasak kayu

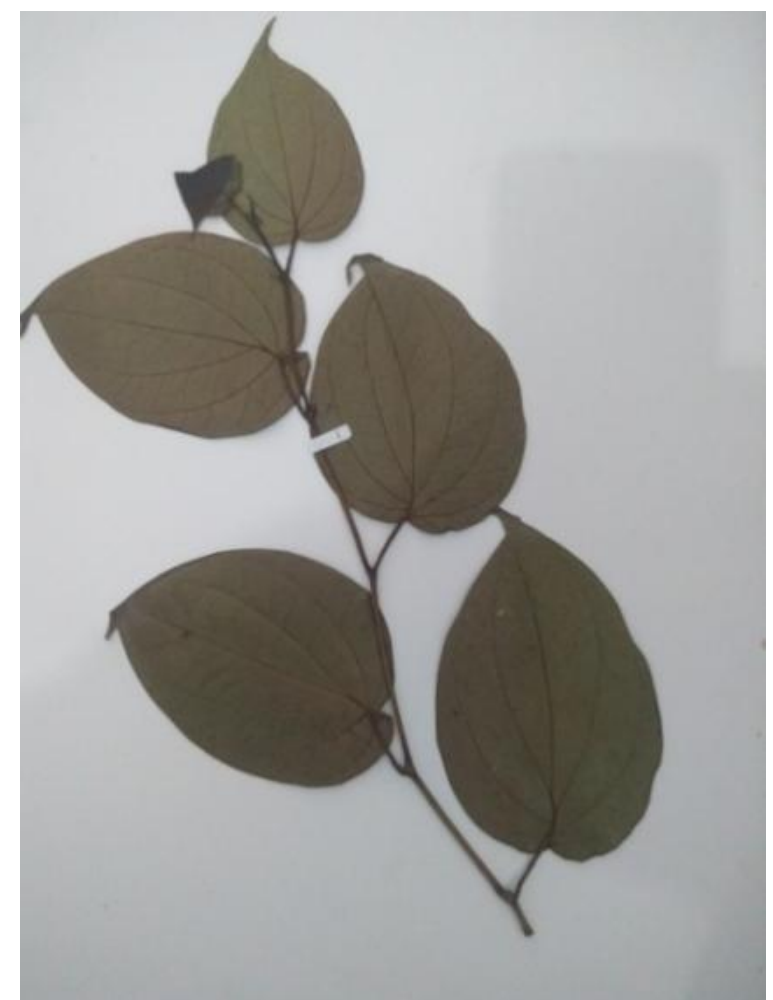

Gambar 12. Contoh spesimen tanaman sirih setelah 72 jam proses pengeringan dengan sasak plat besi 


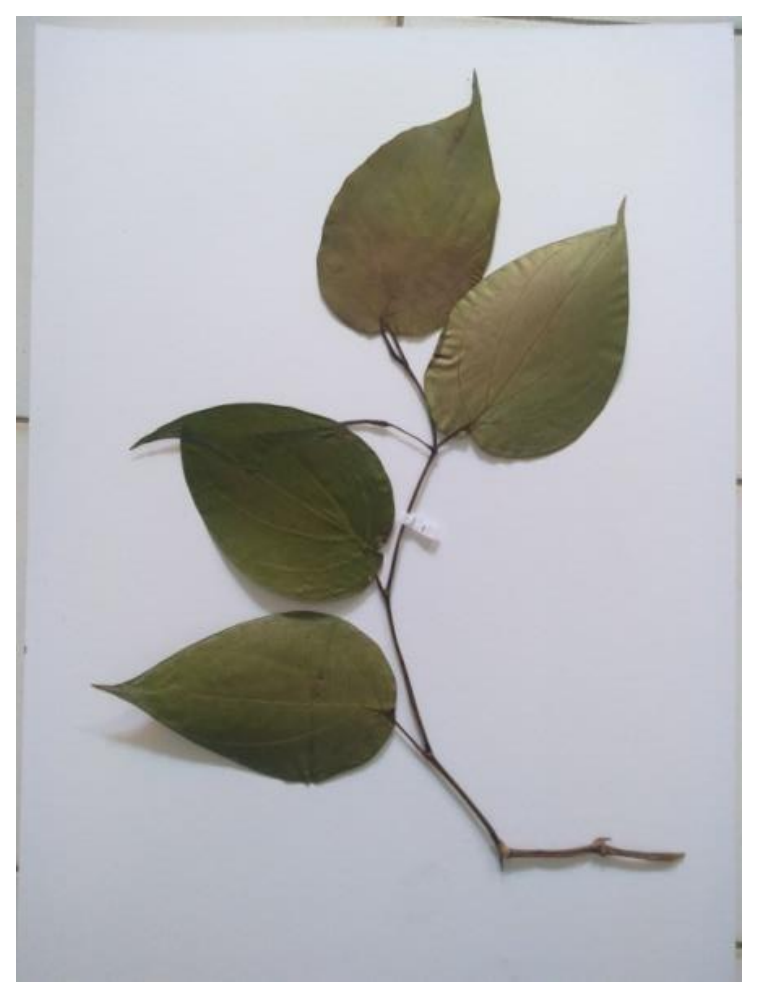

Gambar 13. Contoh spesimen tanaman sirih setelah 72 jam proses pengeringan dengan sasak besi bulat

Dari ketiga contoh spesimen tanaman di atas, terlihat bahwa spesimen hasil pengeringan dengan sasak kayu berada dalam kondisi yang paling baik. Kondisi tanaman utuh dengan warna yang terjaga sesuai warna asli tanaman. Hasil terbaik berikutnya adalah spesimen hasil pengeringan dengan sasak besi bulat. Kondisi tanaman utuh dan baik, warna alami tanaman terjaga $70-80 \%$. Sedangkan spesimen hasil pengeringan dengan sasak plat besi berada dalam kondisi yang paling jelek. Pengeringan tidak sempurna, tanaman lebih lembab dan warna berubah.

\section{KESIMPULAN}

Dari penelitian ini penulis mengambil beberapa kesimpulan sebagai berikut :

1. Sasak berbahan besi bulat terbukti menjadi alat yang mampu meningkatkan proses penguapan air spesimen.

2. Sasak berbahan besi bulat menghasilkan spesimen dengan kualitas yang cukup bagus pada kondisi pengoperasian yang telah dilakukan.

3. Sasak berbahan besi plat terbukti gagal meningkatkan proses penguapan air spesimen.

\section{DAFTAR PUSTAKA}

---. Cara Uji Makanan dan Minuman. 1992. SNI 01-2891-1992. Badan Standardisasi Nasional. Jakarta.

Alim, Mohammad Istajarul, Dina Mardiana, Anita Dwi A, and Diky Anggoro. 2017. Uji Konduktivitas Termal Material Non Logam. Departemen Fisika Institut Teknologi Sepuluh November (ITS). Surabaya.

Antonius Dian Pratama. 2017. Penentuan Nilai Koefisien Konduktifitas Termal Pada Beberapa Jenis Kayu Menggunakan Sensor Suhu Dan Logger Pro. Program Studi Pendidikan Fisika Jurusan Pendidikan Matematika Dan Ilmu Pengetahuan Alam. Fakultas Keguruan Dan Ilmu Pendidikan. Universitas Sanata Dharma. Yogyakarta. 
Heri Sujadmiko, Drs., M.Si., Susarsi Sabbithah, Dra., \& Sri Sulastri, Dra. 2012. Praktikum Taksonomi Tumbuhan Rendah (Edisi 2). Modul 1 : Koleksi Tumbuhan Alga Dan Lumut. Universitas Terbuka. Tangerang Selatan.

Irnin Agustina Dwi Astuti. 2015. Penentuan Konduktivitas Termal Logam Tembaga, Kuningan, Dan Besi Dengan Metode Gandengan. Universitas Indraprasta PGRI, Jakarta Timur. Prosiding Seminar Nasional Fisika Dan Pendidikan Fisika (SNFPF) Ke-6 2015. Volume 6 Nomor 12015.

Mumung Kartasasmita \& Wahyu Dian Laksanawati. 2015. Uji Konduktivitas Termal Pada Bahan Masonite Dengan Stim Generator Td 8556. Jurnal Pendidikan Fisika. Vol. 3 No.2. Tahun 2015. Universitas Muhammadiyah Metro.

Netty Kurniawati. April 1999. Penentuan Konduktivitas Termal (K) Beberapa Jenis Logam : Aluminium Murni, Baja Tahan Karat (18\% Cr, 6 \% Ni) Dan Baja Karbon $(0,5 \%$ C). Jurusan Fisika Fmipa Universitas Sriwijaya. Jurnal Penelitian Sains; Hal 38-48. No. 5 April 1999. Palembang.

Sugiyono. 2006. Metode Penelitian Pendidikan : Pendekatan Kuantitatif, Kualitatif, dan $R \& D$. Penerbit Alfabeta. Bandung.

Syamswisna. 2011. Penggunaan Spesimen Herbarium Tumbuhan Tingkat Tinggi (Spermatophyta) Sebagai Media Praktikum Morfologi Tumbuhan. Jurnal Guru Membangun, Vol. 26 No. 2 Tahun 2011. Universitas Tanjung Pura. Pontianak.

Titi Kolimo. 2014. Panduan Teknis Pengumpulan Herbarum Rotan. Badan Penelitian Dan Pengembangan Kehutanan Pusat Penelitian Dan Pengembangan Konservasi Dan Rehabilitasi Bogor. Bogor.

https://teknologihutan.fkt.ugm.ac.id/wp-

content/uploads/sites/675/2019/01/KONDUKTIVITAS_PANAS_EMPAT_JENIS_KA YU_DALAM_KONDISI_KADAR_AIR_YANG_BERBEDA-1.pdf 